The Center for Talented Youth Spain: an initiative to serve highly able students

Javier Tourón, Marta Tourón and Marta Silvero

University of Navarra, Spain, Center for Talented Youth Spain

This paper deals with the main aspects of the work carried out by the Center for Talented Youth Spain since its founding. The educational model applied here is based on the 'Study of mathematically precocious youth', developed by Julian Stanley in the early seventies and currently the inspiration behind all the centers belonging to Center for Talented Youth International. We provide data from the SCAT ('School and college ability test') test, validated in Spain by the first author, which is used to identify students with exceptional verbal or mathematical ability. The results obtained are analyzed in the light of theoretical models, highlighting the similarities between the results obtained and those in the USA. Moreover, we explore data on course development and student assessment of courses. Finally, we explore the future prospects for the Center and of highly able students in Spain.

\title{
Introduction
}

The education of the most able students in Spain continues to be a topic that is clearly not a priority for our schools or government. Although the laws pertaining to education make clearly indicate the importance of and need to attend to the diversity of the student body, this diversity is frequently limited to students with learning disabilities and, most recently, immigrant students.

The educational treatment of intellectually gifted students is expressly covered in various legislative documents, for example Royal Decree 696/1995 among others, that also discuss the intricacies of this topic. Most recently the education of gifted students has been discussed in article 43 of the Law of Quality in Education, developed by Royal Decree 943/2003. Nonetheless, the professional training of teachers and assignment of economic resources to facilitate the education of students with greater learning potential are at levels still far from acceptable. One fact suffices to illustrate this. If we consider that high ability students form between 2 and $3 \%$ of any population, in Spain without a university level education, we would be talking about some 200,000 students, of which only a few hundred have so far been identified and, despite their identification, these are not always well attended to educationally. In order to promote the development of talent educational intervention is necessary, and in order to do this we must know with whom we are to pursue this intervention and how we are to pursue it. So, until we undertake the process of identification of high ability students and the professional training of those teachers who will work with them, we will remain in a precarious position.

Our work on the education and attention of the most able students began at the University of Navarra in 1994. After a few general studies on giftedness and its identification (see, for example, Tourón, 1998; Tourón et al., 1999) we came across the model developed by Dr Julian Stanley in 1971, the evolution of which led to the establishment of the Center for Talented Youth (CTY) at Johns Hopkins University (Baltimore, Maryland) in 1979, which last year celebrated its 25th 
anniversary. The model inspiring CTY evolved from the 'Study of mathematically precocious youth', which is currently conducting a 50 year longitudinal study, of which 30 years results have already been published (available online at: http://peabody.vanderbilt.edu/ depts/). As a result of the studies and research conducted in this field we decided to spearhead a Center specifically concerned with the education of high ability students, the Center for Talented Youth Spain, the second charter member of Center for Talented Youth International. [Information about CTYI can be found at: http://www.ctys.net/quees2.html (in Spanish); http://www.cty.jhu.edu/about/ctyintl.html (in English).]

One of the key elements of the CTY model is the process of identification, the talent search, for which results are published annually, not only for the process undertaken by CTY, but for that undertaken by other universities which have also implemented this model (e.g. Denver, Northwestern, Duke and Arizona). The CTY model clearly has the greatest extension in practice and is the model on which the greatest volume of research is available. We have conducted a quasi-exhaustive literature review on the subject (Reyero \& Tourón, 2003).

The purpose of this paper is two-fold. First, we present an overview of the results obtained by applying this model in Spain through the work of the Center for Talented Youth Spain. Second, we will discuss the development and evaluation of programs offered during our first 3 years of serving highly able students.

The talent search with the 'School and college ability test' (SCAT)

The 'School and college ability test' (SCAT) was originally developed by ETS (Princeton) in the early 1970s and is now owned by CTY (Johns Hopkins University). The test has two separately timed parts: verbal, which uses analogy items to measure a student's understanding of words; quantitative, which tests a student's understanding of fundamental number operations through quantitative comparison items with a minor emphasis on reading. The test yields three scores: verbal, quantitative and total. Students are given $\mathbf{4 0}$ minutes to complete the test, 20 minutes for each part. The test is designed to measure the verbal and quantitative abilities of students in Grades 3-12. There are two forms ( $X$ and $Y$ ) and three levels of difficulty.

The first step was to validate the SCAT in Spain, a process which began in 1997, after achieving agreement with CTY, and ended in 2000. From that point CTY Spain has been using the SCAT under license from CTY in Baltimore. Several papers discussing the validation process have been published in recent years (Brody et al., 2001; Tourón \& Reyero, 2003), so that here we will only present an overview of the psychometric properties of the test, in order to focus on the results obtained from its use in the identification process in Spain (according to the previously mentioned talent search model).

Table 1 presents the difficulty and discrimination parameters for Test Form $\mathrm{X}$, according to the results obtained from the Spanish validation. As is evident, the measure of difficulty increases with each grade within each level of the test, as expected. On the other hand, the level of difficulty is not high in the upper grades of each level, which clearly demonstrates a possible ceiling effect of 
the test. This effect is common to all tests, providing even greater support for the 'above grade level' measuring process undertaken in the talent search.

Table 1. Difficulty and discrimination indexes of the Spanish version of SCAT (Form $X$;

\begin{tabular}{|c|c|c|c|c|c|}
\hline \multirow[b]{2}{*}{ SCAT level } & \multirow[b]{2}{*}{ Grade } & \multicolumn{2}{|c|}{ Difficulty } & \multicolumn{2}{|c|}{ Discrimination } \\
\hline & & Verbel $\mathrm{X}$ & Quantitative X & Verbal X & Quantitative X \\
\hline & $3 r d$ & 0.40 & 0.34 & 0.53 & 0.56 \\
\hline \multirow[t]{3}{*}{ Elementary } & 4th & 0.52 & 0.46 & 0.53 & 0.52 \\
\hline & Sth & 0.66 & 0.66 & 0.56 & 0.51 \\
\hline & $6 \mathrm{th}$ & 0.52 & 0.50 & 0.49 & 0.46 \\
\hline \multirow[t]{3}{*}{ Intermediate } & $7 \mathrm{th}$ & 0.59 & 0.59 & 0.51 & 0.46 \\
\hline & 8th & 0.64 & 0.64 & 0.52 & 0.52 \\
\hline & $9 \mathrm{hb}$ & 0.53 & 0.56 & 0.43 & 0.50 \\
\hline \multirow[t]{3}{*}{ Advanced } & $10 \mathrm{hh}$ & 0.59 & 0.64 & 0.41 & 0.50 \\
\hline & 1 lth & 0.62 & 0.66 & 0.44 & 0.49 \\
\hline & $12 \mathrm{th}$ & 0.65 & 0.70 & 0.41 & 0.50 \\
\hline
\end{tabular}

The discrimination values can be considered acceptable for most of the levels, although discrimination is lower in the verbal section at the advanced level. It will require a more careful inspection of some of the items and the development of new ones.

Table 2 captures the reliability values expressed as internal consistency. As is clearly evident, these values are more than acceptable, especially when we look at the overall test. Nonetheless, it is necessary to improve some of the verbal sections at the advanced level in order to increase the level of reliability.

Table 2. Indices of internal consistency (Cronbach's $\alpha$ ) for SCAT (Form X)

\begin{tabular}{lrccc}
\hline SCAT level & Grade & Verbal X & Quantitative X & Total \\
\hline \multirow{3}{*}{ Elementary } & 3rd & 0.88 & 0.87 & 0.92 \\
& 4th & 0.87 & 0.86 & 0.91 \\
& 5 th & 0.88 & 0.86 & 0.92 \\
Intermediate & 6 th & 0.84 & 0.83 & 0.90 \\
& 7th & 0.84 & 0.86 & 0.91 \\
Advanced & 8 th & 0.88 & 0.87 & 0.91 \\
& 9 th & 0.81 & 0.83 & 0.88 \\
& 10 h & 0.80 & 0.83 & 0.88 \\
& 11 th & 0.79 & 0.85 & 0.88 \\
\hline
\end{tabular}

Using the SCAT test in the talent search process at CTY Spain

There are two steps in the CTY identification process, based on the SMPY developed by Stanley, one 'in grade level' and the other 'above grade level', which allows identification of a student's level avoiding the ceiling present in 'in grade level' measures. There are numerous detailed descriptions of this model (Stanley \& Benbow, 1981, 1982, 1983, 1986; Goldstein et al., 1999). 
In Spain there are no general systematic processes for assessing students. CTY Spain has not yet been able to establish a talent search in a generalized way and has limited its work to identification in schools that show an interest in the process and to individual diagnostic testing of individuals that contact the Center.

The results offered below refer to evaluations made from these two sources. Given that the in grade level' step also uses SCAT, the procedure followed is to evaluate students according to their age with a corresponding level of that test. Those students scoring in the 95th percentile or higher in either the verbal or quantitative section are re-evaluated with a higher level SCAT. This is the case with elementary school students, with whom we are concerned here, as shown in Figure 1.

As indicated in Figure 1, students scoring in the 95th percentile in one of the sections of the in grade level' test are re-evaluated and their scores compared with those of students 2-3 years ahead of them. This step allows us to determine the 'degree of talent' while avoiding the ceiling effect common to most tests. The ceiling effect occurs, as is well known, when items on a test are not sufficiently difficult for the most able students.

Tables 3 and 4 summarize the results obtained after testing 350 students in Grades 3-6 (in grade level) and what is equivalent to Grades 7-8 (above grade level). The results in these tables refer to the 65 students (approximately $20 \%$ of the total number of students tested) performing at the 95th percentile or higher in the 'in grade level' phase of the process. Given the limited space available, only a few of the more significant aspects are mentioned

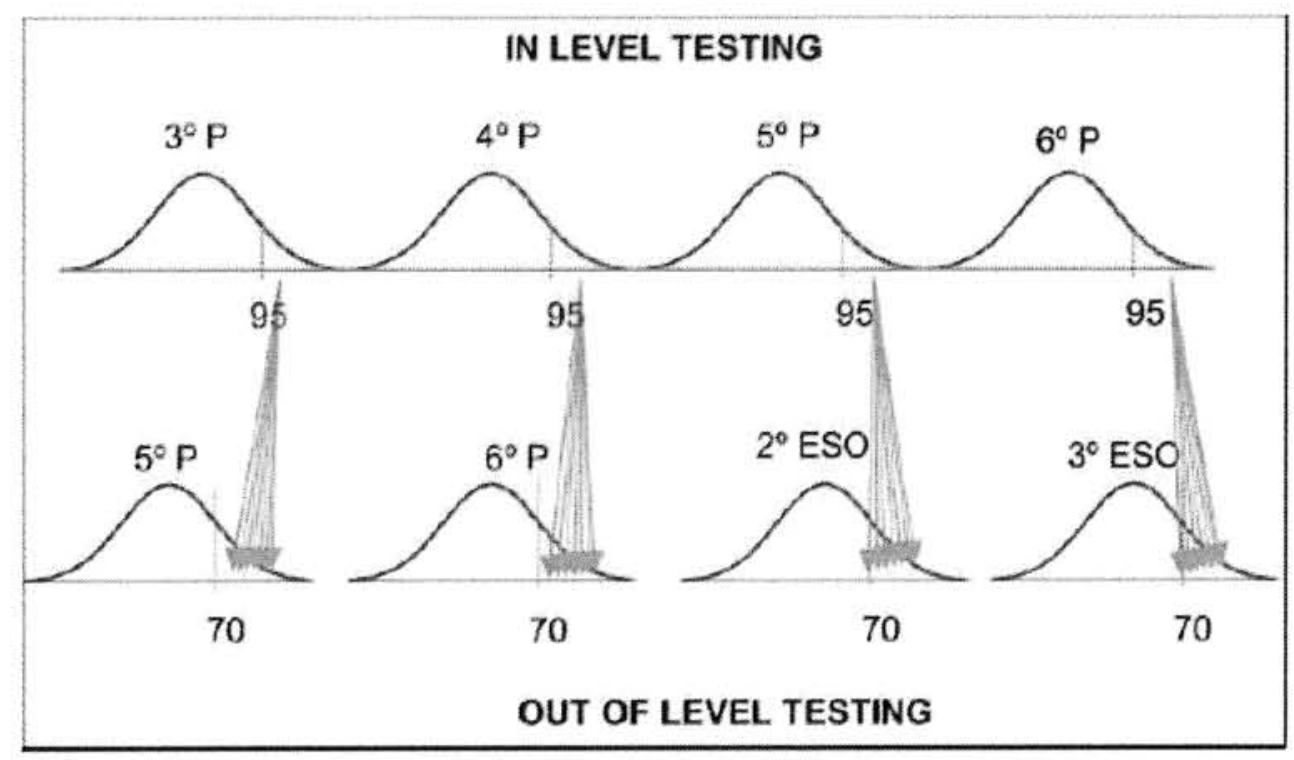

Figure 1. In grade level and above grade level testing process for Grade $3-6$ students ( $2^{\circ}$ ESO and $3^{\circ}$ ESO are equivalent to Grades 7 and 8) using SCAT 
Table 3. Percentages of students in 'abowe grade level' testing according to their 'in grade level' results in the Quanititative section of SCAT

\begin{tabular}{llllll}
\hline & \multicolumn{5}{c}{ In level percentiles } \\
\cline { 2 - 6 } Out of level percentiles & 95 & 96 & 97 & 98 & 99 \\
\hline$<50$ & 27 & 33 & 40 & 8 & \\
$51-60$ & 18 & & 20 & 25 & \\
$61-70$ & 18 & 33 & 40 & 33 & 19 \\
$>70$ & 36 & 33 & & 33 & 80 \\
\hline
\end{tabular}

Values are expressed as percentages $(n=63)$.

Table 4. Percentages of students in 'above grade level' testing according to their 'in grade level' results in the Verbal section of SCAT

\begin{tabular}{lrrrrr}
\hline & \multicolumn{5}{c}{ In level percentiles } \\
\cline { 2 - 5 } Out of level percentiles & 95 & 96 & 97 & 98 & 99 \\
\hline$<50$ & 18 & & & 12 & \\
$51-60$ & 45 & 20 & & 6 & 4 \\
$61-70$ & 9 & 60 & 80 & 31 & 8 \\
$>70$ & 27 & 20 & 20 & 62 & 88 \\
\hline
\end{tabular}

Values are expressed as percentages ( $n=63)$.

First of all, students scoring in the 95th percentile obtain high scores in above grade level tests (23 years more advanced) with relatively high frequency, almost always scoring above the 50th percentile. In only a few cases do these students reach their ceiling with an in grade level test.

The majority of students scoring in the highest percentiles (96-99\%) in in grade level tests tend to also score in the higher percentiles in above grade level tests.

It is clear as well that in all groups of students scoring in the same percentile on in grade level tests there is a relative dispersion of percentiles on above grade level tests, illustrating the great diversity of abilities within apparently homogeneous groups.

At the same time, as clearly depicted in Figures 2 and 3, in both sections of the tests the higher the percentile obtained in the in grade level phase the higher the percentile obtained in the above grade level phase, thus illustrating the higher ceiling effect for those students scoring in the upper region of the in grade level test. Likewise, it seems clear that, albeit with a degree of heterogeneity, those students with the higher in grade level scores (particularly in the 99th percentile) tend to obtain above grade level scores in the 70th percentile or above when compared with students 2 or even 3 years older.

These results demonstrate the consistency of the model since it was originally developed and show that it reproduces in a clear manner the same pattern of results despite the differing cultural context. This difference clearly has no effect on the evaluation of human abilities. It is evident that 
above grade level measurement is necessary in order to determine the degree of talent of students whose potential would be inadequately evaluated with an in grade level measure. We again emphasize the importance of establishing systematic processes of identification of talent in order to serve the needs of many students who otherwise would not have the opportunity to find appropriate means of developing their talents.

Next we examine several aspects related to the development of programs and their evaluation.

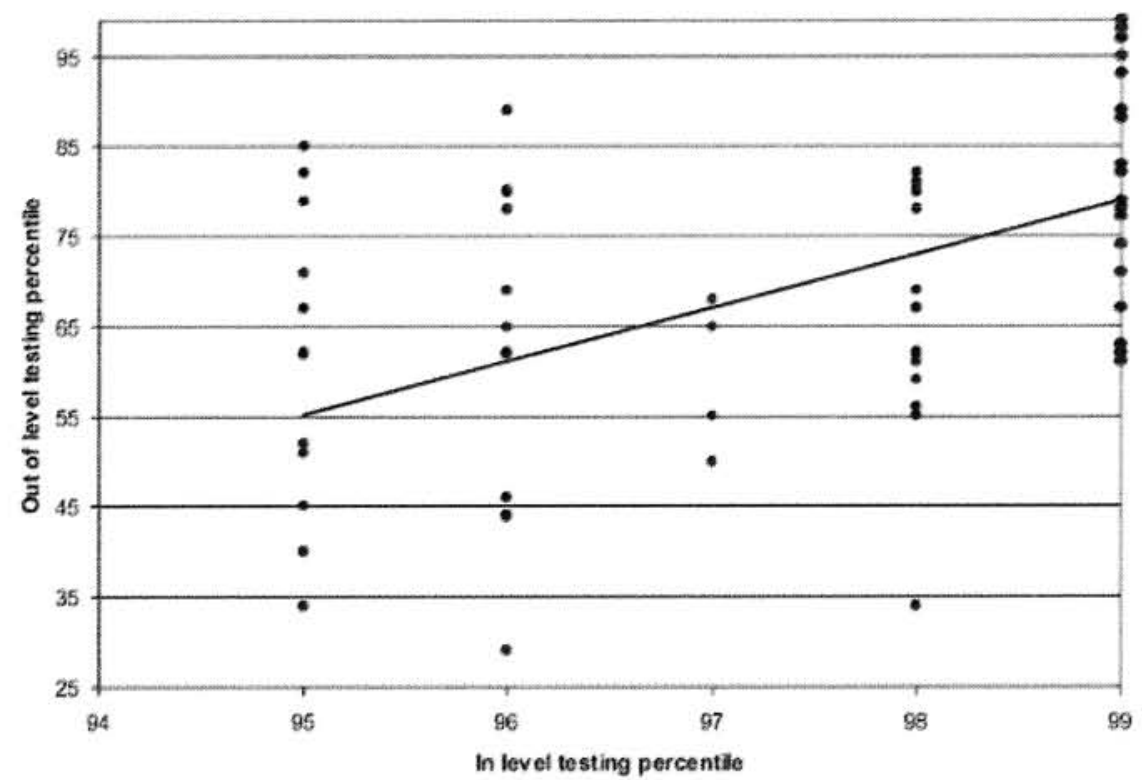

Figure 2. Primary students in grade level test scores compared with above grade level test scores in the SCAT Quantitative section 


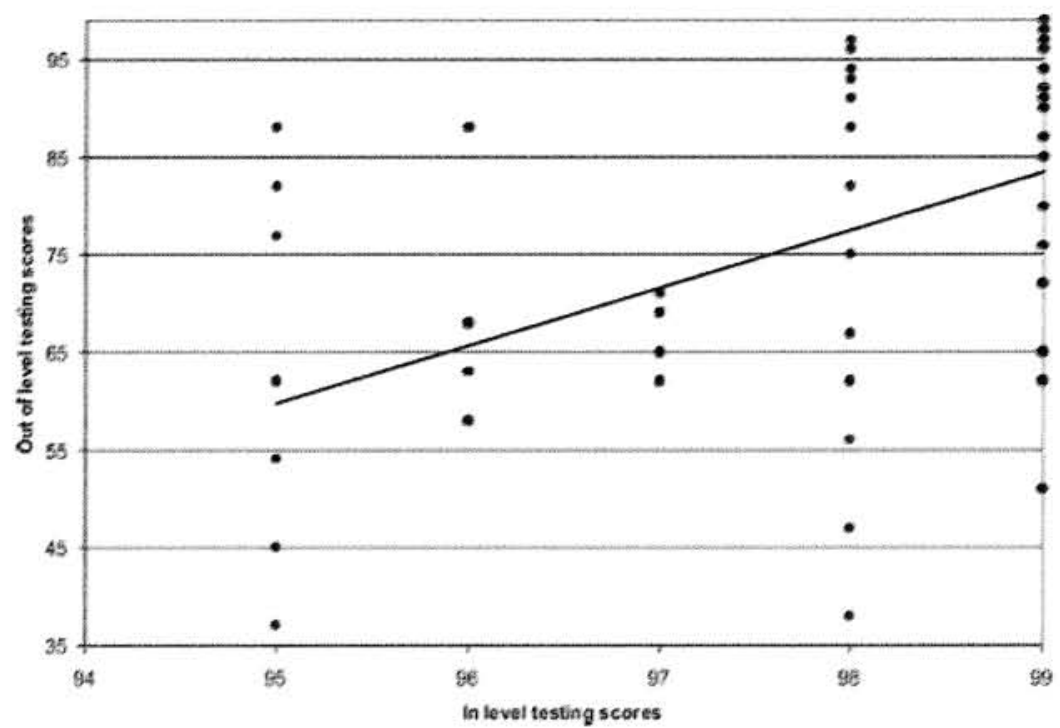

Figure 3. Primary students in grade level test scores compared with above grade level test scores in the SCAT Verbal section

CTY Spain programs: general characteristics

Below we outline some of the characteristics of the educational intervention initiatives implemented at CTY Spain.

Our aim at CTY Spain is to make the level of all educational programs sufficiently challenging. We attempt to achieve this by constantly adapting to the learning pace and level of students, in line with the principal of 'optimal match', which can be defined as 'the adjustment between a suitably challenging curriculum and the pace and level of learning shown by the student' (Center for Talented Youth, 1995, p. iv). This principle is clearly at odds with inflexible 'one size fits all' educational systems. In contrast, the philosophy behind the programs run by CTY Spain, like the other centers belonging to CTY International, is based on catering to the individual needs of each student. We follow the DTPI (diagnostic testing followed by prescribed instruction) model in this instance (see Benbow \& Lubinsky, 1997, for a description), which is based on two fundamental principles: first, determining a student's command of a particular subject and, second, monitoring the student's learning pace on a regular basis in order to adapt the pace of instruction to this learning pace.

This academic initiative is aimed at high ability students and students must be tested before being accepted onto the program. Such evaluations should place the student at least in the top $5 \%$ of his/her age group in the in grade level phase and at or above the 60th percentile in the above grade level phase (this cut-off point is not inflexible and can vary slightly according to the individual circumstances of each student). In this assessment process CTY Spain uses SCAT, as mentioned above. In some cases, if the students have already been diagnosed and the tests 
performed on them are acceptable, they can enroll on the program directly. In addition, parental nominations, suitably justified, may also be accepted on parental responsibility and the guidance of CTY Spain personnel.

As the programs we run cover a wide range of subjects, students select an area of interest to them, which ensures that they are highly motivated in their study. They can often study subjects outside the school curriculum, thus most of the programs we offer can be classed as enrichment programs.

Students find a suitable framework in which to study subjects in depth, working at the right pace and at a sufficiently challenging level. We apply a fully individualized teaching model, with a student ratio that does not exceed 10:1, which enables us to adapt to the learning rate and potential problems of each student.

Students attending these programs have the opportunity to meet other students who share the same concerns, which not only facilitates learning but also coexistence. The prime objective of these programs is to develop individual talent, therefore the academic input is essential. Nonetheless, the attention students receive is part of a global approach, encompassing their social and emotional needs as well as their academic development.

The range of educational programs on offer include courses targeted at students of all ages within the formal Spanish education system, from kindergarten to Grade 12. However the groups on the annual programs are organized according to the intellectual capacity of the students and their level of interest and ability in the subject concerned and not according to Grade, although the latter is a point of reference as regards deciding which programs are offered to a student.

Instructors at the CTY Spain are all highly qualified in their chosen fields (university degree or Ph.D.), in addition to which they receive specialized training in teaching students of high ability. Moreover, instructors are supported by an in class assistant instructor who collaborates directly with them in the process of monitoring the progress made by the students.

Naturally the timing of these programs varies according to type. In the annual programs students attend a weekly 2 hour session during the official school year (October-June). In the summer we run intensive 3 week courses with 4 or 5 hour sessions, depending on the age of the students. The total length of both programs is similar, 75 hours in total.

Finally, it is worth noting that students completing the program receive a Diploma from the Center for Talented Youth Spain, a member of CTY International, based at Johns Hopkins University (Baltimore, MD). 
Type of programs

There are two types of programs, annual and summer courses.

Annual programs. The annual programs can be divided into several categories according to the subject involved. The Center runs science, humanities, social and technological courses. It also runs intensive courses, which generally work on psycho-educational themes, adopting a highly practical approach, and aim to equip the student with a series of instrumental skills to nurture his/her all round development and training. The two courses listed below are prime examples of this.

Social skills. Taking into account that interpersonal communication is an essential part of human activity, this program aims to teach students how to assimilate and develop a series of basic skills to maintain optimal relationships with others. Fundamental emotional processes are worked on (assertiveness, empathy, etc.), teaching students to regulate them in an intelligent way (decisiontaking, resolving conflicts, etc.).

Strategies for effective study. The aim of this program is to offer students the opportunity to acquire a series of tools that facilitate their intellectual work. These tools include mnemonic rules, comprehension techniques, reading speed, creating schemes, diagrams, conceptual maps, note taking, etc. It is also worth mentioning here a special element of the program, the mentor plan. This program is designed for students in the last stage of schooling and focuses on the following areas:

- guidance of students towards a specific area of study (humanities or science) for which she/he shows high motivation and a particular interest;

- study of this subject with a university expert or mentor who will propose a research project that she/he will develop throughout the course;

- student and mentor meetings once a week to discuss results and set the week's work.

The aim of this work plan is to introduce students to the university and research world, allowing them to gain insight into an area of knowledge that they may elect to pursue in the future, as well as the work methodology used in this area.

Summer programs: non-residential and residential. There are two types of summer programs, depending on the ages of the students: non-residential and residential. The work ethos behind the non-residential campus programs is the same as that of the residential campus programs, but with a few notable differences. These programs are aimed at the youngest students, from 4 to 9 years old. As they are targeted at the youngest students, there are fewer hours of classwork, although they still foster the preferred areas of knowledge of each student at a suitable level of depth and challenge. The courses range between 30 and 60 hours, spread over 3 weeks, depending on the ages of the students. 
At the residential summer campus the academic work is complemented by social, sporting and cultural activities, which are also important for the development of the student. The campus provides students with a unique opportunity to experience, perhaps for the first time, living with their intellectual peers.

The program consists of 5 hours of classwork and 2 hours of study a day. During the study time they dedicate 2 hours a week to English and 2 hours to developing learning strategies. English speaking students have approximately 4 hours a week of Spanish. The rest of the time is dedicated to sports and cultural activities.

The programs developed at the residential summer campus cover a wide range of subjects within the framework of the so-called liberal arts, encompassing language, history or art, mathematics and sciences or computing. The programs taught can be classified as enrichment programs in the sense that they do not mirror the school curriculum, although they can base themselves on it where necessary. Students attending the residential campus select one program from those available for their age group and classes are dedicated to this area during the 3 weeks of the course.

The students are supervised by an instructor and assistant instructor during academic classes and by a monitor for the rest of the day. There is one monitor for every 10 students.

Table 5 summarizes the main data referring to the educational intervention initiatives carried out by CTY Spain in the period 2000 and 2004. It displays the various programs offered on an annual basis or as summer courses and the number of years these programs have been running, as well as student numbers. 
Table 5. Summary of the programs oflered by CTY Spain in the period $2000-2004$

\begin{tabular}{|c|c|c|c|c|c|c|c|}
\hline Program & Area & Grades & Editions & Students & Hours & Type & Language \\
\hline The learning adventure & Special programs & $\begin{array}{l}\text { Kindergarten, } \\
1 \& 2\end{array}$ & $2000-2005$ & 44 & 72.75 & PANRSC & Spanish \& Englist \\
\hline Smatt web pages & Techrology & 3.5 & $\begin{array}{l}2001 / 2003 / \\
2004\end{array}$ & 9 & 72 & $\mathrm{PA}$ & Spanish \\
\hline $\begin{array}{l}\text { Talking kelps us understand } \\
\text { others }\end{array}$ & $\begin{array}{l}\text { Humanities and social } \\
\text { sciences }\end{array}$ & 35 & 2001 & 5 & 72 & $\mathrm{PA}$ & Spanish \\
\hline The molecular logic of life & Math and S cience & 3.5 & 2001 & 4 & 72 & PA & Spanish \\
\hline Learning through research & $\begin{array}{l}\text { Humanities and social } \\
\text { sciences }\end{array}$ & 3.5 & 2001 & 2 & 72 & $\mathrm{PA}$ & Spanish \\
\hline $\begin{array}{l}\text { Creative math: logic and } \\
\text { imagination } 1\end{array}$ & Math and science & 3.5 & $\begin{array}{l}2002 / 2003 \\
2004\end{array}$ & 14 & 72 & PA & Spanish \\
\hline $\begin{array}{l}\text { Creative math logic and } \\
\text { imagination } 11\end{array}$ & Math and science & $5 \cdot 6$ & $2003 / 2004$ & 22 & 72.75 & PARSC & Spanish \\
\hline $\begin{array}{l}\text { The long night of the } \\
\text { Pharaobs }\end{array}$ & $\begin{array}{l}\text { Humanities and social } \\
\text { sciences }\end{array}$ & $3-5$ & 2002 & 2 & 72 & PA & Spanish \\
\hline $\begin{array}{l}\text { Introduction to } \\
\text { programuning }\end{array}$ & Technology & 6.8 & $2002 / 2004$ & 21 & $72-75$ & $\begin{array}{l}\text { PANRSC } \\
\text { RSC: }\end{array}$ & Spanish \\
\hline Computer programuning & Technology & $7-10$ & $2003 / 2004$ & 7 & 72 & $P A$ & Spanish \\
\hline Time is precious & Special programs & 56 & 2002 & 2 & 72 & PA & Spanish \\
\hline $\begin{array}{l}\text { Travelers and travels in } \\
\text { literature }\end{array}$ & $\begin{array}{l}\text { Humanities and social } \\
\text { sciences }\end{array}$ & 3.5 & 2003 & 2 & 72 & PA & Spanish \\
\hline $\begin{array}{l}\text { Applied math: reasoning } \\
\text { and the imagination }\end{array}$ & Math and science & $7-10$ & $2003 / 2004$ & 19 & $72-75$ & PARSC & Spanish \\
\hline Physics and dhemistry & Math and science & $7-10$ & 2004 & 5 & 72 & PA & Spanish \\
\hline Introduction to literature & $\begin{array}{l}\text { Humanities and social } \\
\text { sciences }\end{array}$ & 5-6 & 2004 & 2 & 72 & PA & Spanish \\
\hline $\begin{array}{l}\text { Strategies for efficient } \\
\text { study }\end{array}$ & Special programs & $11-12$ & 2004 & 6 & 20 & $\begin{array}{l}\text { Intensive } \\
\text { course }\end{array}$ & Spanish \\
\hline Social skills & Special programs & 1112 & 2004 & 10 & 20 & $\begin{array}{l}\text { Intensive } \\
\text { course }\end{array}$ & Spanish \\
\hline
\end{tabular}

Table 5. (Continacd.)

\begin{tabular}{|c|c|c|c|c|c|c|c|}
\hline Program & Area & Grades & Editions & Students & Hours & Type & Language \\
\hline Mentor plan & Special programs & $11-12$ & $2002 / 2003$ & 4 & $\begin{array}{l}\text { Weekly } \\
\text { meeting }\end{array}$ & PA & Spanish \\
\hline Ecology: our environment & Math and science & 46 & $2002 / 2004$ & 9 & $72-75$ & PAIRSC & Spanish \\
\hline Writing and the imagination & $\begin{array}{l}\text { Humanities and social } \\
\text { sciences }\end{array}$ & 34 & 2004 & 4 & 75 & NRSC & Spanish \\
\hline Heroes and villains & $\begin{array}{l}\text { Humanities and social } \\
\text { sciences }\end{array}$ & 6.8 & 2004 & 3 & 75 & RSC & Spanish \& English \\
\hline $\begin{array}{l}\text { Archeology: digging up the } \\
\text { past }\end{array}$ & $\begin{array}{l}\text { Humanities and social } \\
\text { sciences }\end{array}$ & 910 & 2004 & 7 & 75 & RSC & Spanish \& English \\
\hline
\end{tabular}

PA, annual program; NRSC, bon-residential summer program; RSC, residential summer program.

Program evaluation

Course assessment with a view to improvement year on year is one of the requisites of the work carried out at the centers belonging to CTY International. In this section we cover some of the aspects relating to student assessment of programs at the end of each course. 
First we can observe a growth in the number of students on the various programs: annual and summer. Figure 4 shows the total number of students at CTY Spain per year since its foundation for annual and summer programs, respectively. The figures shown are modest, but growth has been sustained year on year.

The student assessments of the courses run by CTY Spain prove one of the most reliable indicators of quality. The students themselves are best placed to judge whether the courses manage to fulfill the objectives set.

The summer courses are the biggest venture in terms of educational intervention undertaken by CTY Spain. Student assessments of this course therefore provide essential information on their development and ongoing improvement. These assessments are carried out using a student questionnaire that covers academic aspects, free time activities, residential matters and a global assessment of the course. Students assess each of these aspects through a series of items eliciting Likert-type responses (on a scale of 1 to 5 , with 5 as the highest), with additional space for comments at the end of the questionnaire. The items in the section on academic aspects refer to the program content (level of challenge and pace, interest, etc.), classroom methodology, preparation and competence of the instructor, relationships with fellow students and grading by the instructor. As far as leisure and free time activities are concerned, students were asked about the workshops, the range of leisure activities on offer (variety, interest, etc.), preparation and competence of the residence assistants, personal attitude (degree of participation in the activities on offer, positive attitude, etc.) and on their relationships with fellow students on the campus. Residential matters include aspects such as facilities at the campus, timetable and distribution of time, residence regulations, meals, etc. Finally, each student makes a global assessment of the summer course, referring to each of the aspects mentioned.

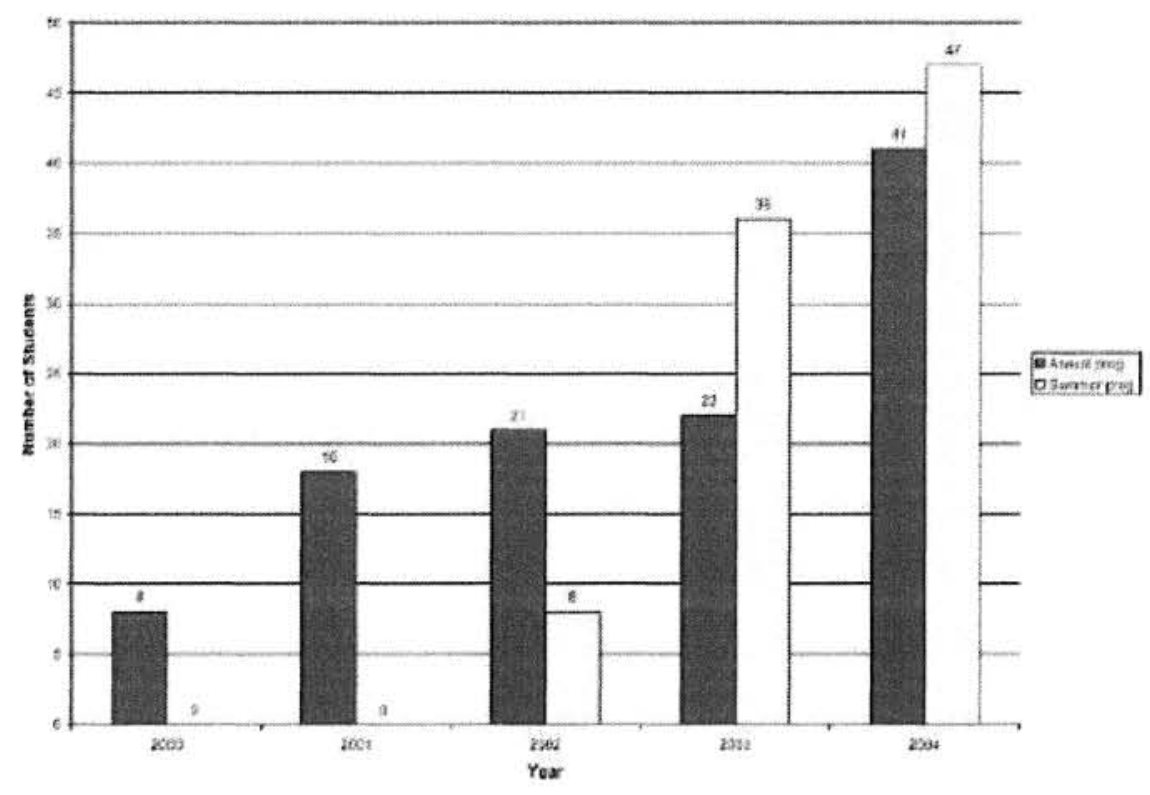

Figure 4. The number of CTY Spain students from its inception 
Figure 5 shows data relating to the assessment exercise for the summer course 2004. As can be seen, all the assessments given are favorable and positive, the global assessment standing at $85 \%$, followed by evaluation of the programs at $81 \%$. The global assessments from previous years (not included in this paper) are above 4 out of a possible 5. Naturally, those in charge of quality assessment analyze the assessments students give for each individual item (which we do not have space to do here) and then take the appropriate actions as regards the next year course.

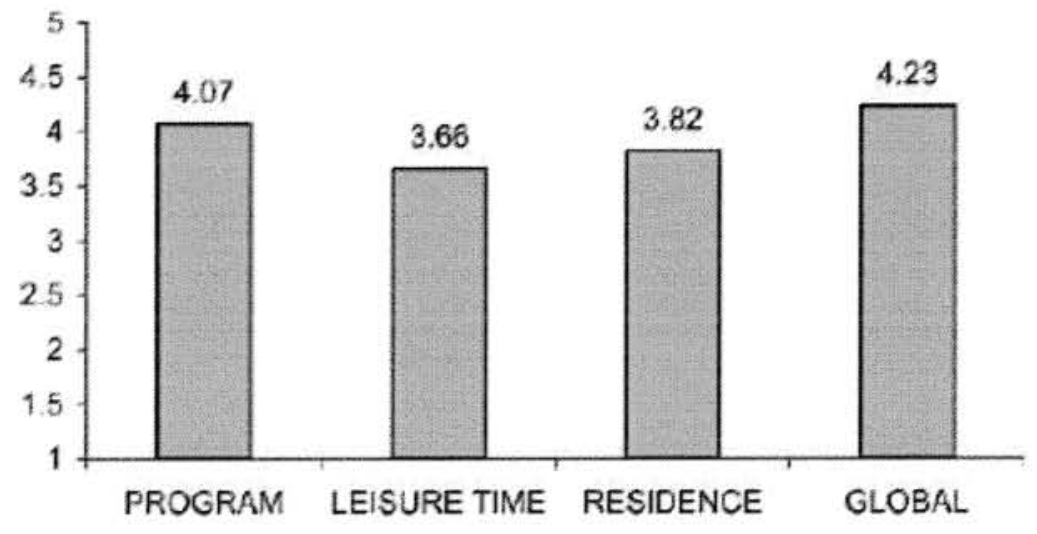

Figure 5. Student evaluations of the 2004 summer program

\section{Future prospects}

The mission of CTY Spain is to serve the maximum number of highly able students in Spain. Students from abroad who are fluent in Spanish or English are also welcome. This objective is also the inspiration for the two projects planned for the immediate future, distance learning and preuniversity programs, targeted at students between the ages of 16 and 18 .

Distance learning courses enable students to follow accelerated learning courses in mathematics, the sciences, new technology and the arts. These courses will be designed for students from the third year of primary education ( 8 year olds) through to the second year of the Baccalaureate (17 year olds). Students must qualify for these programs just like any other program run by CTY Spain, and the development model will be the same as described above. The students will receive individualized attention from highly qualified tutors and the low instructor/student ratio enables them to monitor each student closely. These courses leverage the tools offered by new technology and foster communication and interaction between the tutor and student, as well as with other distance learning students (E-mail, internet discussion forums, interactive whiteboards, fax, etc.). The schedule may vary to suit each student and programs may last between 3 and 6 months. The tutors of the CTY distance programs will be highly qualified specialists in their chosen field of study. Naturally, many of them will have already acted as instructors on the summer courses, which means they that will be familiar with the academic needs of highly able students. Notwithstanding, the tutors receive specialized instruction and training by CTY Spain in serving 
highly able students and in handling the technology used, as well as in the specific courses they are going to conduct.

From its inception CTY Spain has, as mentioned above, offered learning intensification or enrichment curricula for highly able students between the ages of 5 and 17 . With older students up to now CTY Spain has used the aforementioned mentor program, which offers students guidance from an expert tutor in their field of interest to direct the student's studies or supervise a short research project in this area. Experience shows us that this plan is effective, but it does not allow students to interact with other students of the same age and level of ability. The experience of being with 'intellectual peers' is critical to the emotional and psychological development of highly able students.

It is important to find the right environment in which students can discover academic work modes and procedures at the highest level. The aim is to develop programs over the school year with a total duration of 90 hours. This initiative could lead to early university entrance, as in other countries (see a review of research into such programs by Reyero \& Tourón, 2003). In this respect several initiatives are already underway at a number of Spanish universities.

\section{References}

Benbow, C. P. \& Lubinski, D. (1997) Intellectually talented children: how can we best meet their needs?, in: N. Colangelo \& G. A. Davis (Eds) Handbook of gifted education (Boston, MA, Allyn \& Bacon).

Brody, L. E., Stanley, J. C., Barnett, L. B., Gilheany, S., Tourón, J. \& Pyryt, M. C. (2001) Expanding the Johns Hopkins talent search model internationally, Gifted and Talent International, 16(2), 94-107.

Center for Talented Youth (1995) Philosophy and program policy, in: Academic acceleration. Knowing your options (Baltimore, MD, Johns Hopkins University Press).

Goldstein, D., Stocking, V. B. \& Godfrey, J. J. (1999) What we've learned from talent search research, in: N. Colangelo \& S. G. Assouline (Eds) Talent development III. Proceedings from the 1995 Henry B. and Jocelyn Wallace national research symposium on talent development (Scottsdale, AZ, Gifted Psychology Press).

Reyero, M. \& Tourón, J. (2003) El desarrollo del talento. La aceleración como estrategia educativa [Talent development. Acceleration as Educational Strategy] (La Corun a, Netbiblo).

Stanley, J. C. \& Benbow, C. P. (1981) Using the SAT to find intellectually talented seventh graders, College Board Review, 122, 3-7.

Stanley, J. C. \& Benbow, C. P. (1982) Educating mathematically precocious youths: twelve policy recommendations, Educational Researcher, 11, 4-9. 
Stanley, J. C. \& Benbow, C. P. (1983) SMPY's first decade: ten years of posing problems and solving them, Journal of Special Education, 17(1), 11-25.

Stanley, J. C. \& Benbow, C. P. (1986) Youths who reason exceptionally well mathematically, in: R. J. Sternberg \& J. E. Davidson (Eds) Conceptions of giftedness (New York, Cambridge University Press).

Tourón, J. (1998) La identificación de alumnos de alta capacidad intelectual: resultados de un proceso de detección temprana en Navarra [The identification of high ability students: results of an early detection process in Navarre], paper presented at I Congreso Internacional de Educación de la Alta Inteligencia, Mendoza, Argentina.

Tourón, J. \& Reyero, M. (2003) The implementation of the talent search concept in Spain, in: P. Csermely \& L. Lederman (Eds). Talent recruitment and public understanding, NATO Science Series Vol. 977925 (Amsterdam, 10s press), 63-76.

Tourón, J., Repáraz, Ch. \& Peralta, F. (1999) The identification of intellectually highly able students as a decision-making process: results of a detection process in Navarre (Spain), High Ability Studies, 10(2), 163-181. 